\title{
Detection and genetic characterization of porcine circovirus 4 (PCV4) in Guangxi, China
}

\author{
chao sun ${ }^{1}$, Qian $\mathrm{Du}^{2}$, Zhixiao $\mathrm{Han}^{2}$, Jingshan Bi ${ }^{1}$, Wei Wang ${ }^{3}$, and Min Zheng ${ }^{4}$ \\ ${ }^{1}$ Affiliation not available \\ ${ }^{2}$ Guangxi University \\ ${ }^{3}$ Institute of Military Veterinary Medicine, Academy of Military Medical Sciences \\ ${ }^{4}$ Guangxi Center for Animal Disease Control and Prevention, Nanning, 530001, People's \\ Republic of China
}

April 28, 2020

\begin{abstract}
Porcine circovirus type 4 (PCV4), a novel circovirus, was first detected in pigs with porcine dermatitis and nephropathy syndrome (PDNS) in China. This study investigated the frequency of porcine circovirus 4 (PCV4) in pigs in Guangxi Province, China, from 2015 to 2019 and its genome diversity. Thirteen of 257 (5.1\%) samples were positive for PCV4, 9 of 13 (69.2\%) PCV4-positive samples were coinfected with PCV2 or PCV3, and one PCV4-positive sample was coinfected with both PCV2 and PCV3. Similar to other PCVs, PCV4 contains two major ORFs and a stem loop (TTCAGTATTAC). Multiple sequence alignments showed that the PCV4 genome shares 25.3-73.8\% nucleotide similarity with other representative circovirus genomes. Interestingly, the PCV4 Cap protein shares relatively high homology (approximately 50\%) with the PCV2 Cap protein and has multiple highly homologous peptides. Multiple amino acid sequence alignments of the Cap protein revealed that PCV2 and PCV4 have multiple highly homologous antigen sites and identical receptor binding sites. Therefore, PCV2 and PCV4 may have cross-protective immunogenicity. Phylogenetic analysis showed that PCV4 is closely related to mink circovirus and bat-associated circovirus. In summary, this was the first seroprevalence and genetic investigation of PCV4 in Guangxi Province, China. The results provide insights into the epidemiology and pathogenesis of this important virus.
\end{abstract}

Title

Detection and genetic characterization of porcine circovirus 4 (PCV4) in Guangxi, China Running Head

Prevalence of novel porcine circovirus 4 (PCV4) in pig populations

Wenchao Sun ${ }^{a}$, Qian Du b, c, Zhixiao Han b, c, Jinshan Bi ${ }^{c}$, Wei Wanga, b, c*, Min Zheng ${ }^{c^{*}}$

a Institute of Virology, Wenzhou University, Wenzhou 325035, China

b College of Animal Science and Technology, Guangxi University, Nanning 530000, China

c Guangxi Center for Animal Disease Control and Prevention, Nanning 530001, China

*Corresponding author

E-mail: wwky1101@126.com (WW), zhgmn26@163.com (MZH).

\section{Summary}


Porcine circovirus type 4 (PCV4), a novel circovirus, was first detected in pigs with porcine dermatitis and nephropathy syndrome (PDNS) in China. This study investigated the frequency of porcine circovirus 4 (PCV4) in pigs in Guangxi Province, China, from 2015 to 2019 and its genome diversity. Thirteen of 257 (5.1\%) samples were positive for PCV4, 9 of 13 (69.2\%) PCV4-positive samples were coinfected with PCV2 or PCV3, and one PCV4-positive sample was coinfected with both PCV2 and PCV3. Similar to other PCVs, PCV4 contains two major ORFs and a stem loop (TTCAGTATTAC). Multiple sequence alignments showed that the PCV4 genome shares 25.3-73.8\% nucleotide similarity with other representative circovirus genomes. Interestingly, the PCV4 Cap protein shares relatively high homology (approximately 50\%) with the PCV2 Cap protein and has multiple highly homologous peptides. Multiple amino acid sequence alignments of the Cap protein revealed that PCV2 and PCV4 have multiple highly homologous antigen sites and identical receptor binding sites. Therefore, PCV2 and PCV4 may have cross-protective immunogenicity. Phylogenetic analysis showed that PCV4 is closely related to mink circovirus and bat-associated circovirus. In summary, this was the first seroprevalence and genetic investigation of PCV4 in Guangxi Province, China. The results provide insights into the epidemiology and pathogenesis of this important virus.

KEYWORDS: Porcine circovirus type 4; Porcine; Epidemiology; Phylogenetic analysis

\section{INTRODUCTION}

Porcine circovirus (PCV), containing a small single-stranded, nonenveloped, closed circular DNA genome, has been reported as one of the smallest viruses and belongs to the genus Circovirus under the family Circoviridae (Tischer et al., 1982). Its genome contains two major open reading frames (ORF1 and ORF2), which encode a replication-associated protein (Rep) and a structural protein (capsid protein, Cap), respectively. Specifically, Cap contains multiple cell epitopes that are associated with virus neutralization (Cao et al., 2018; Mayr et al., 1968).

Three major genotypes of PCV have been reported. Porcine circovirus type 1 (PCV1) was first identified as a contaminant in a pig kidney cell culture (PK-15) and is considered nonpathogenic (Cao et al., 2018). However, PCV2 and PCV3 are the causative agents of multiple clinical diseases in swine and result in substantial economic losses for the pig industry worldwide (Meng, 2013; Palinski et al., 2017; Sun et al., 2019; Wang et al., 2019). In a recent report, porcine circovirus type 4 (PCV4), a novel and genetically divergent porcine circovirus, was first revealed in Hunan, China. PCV4 is suspected to be associated with severe clinical disease involving respiratory signs, enteric signs and porcine dermatitis and nephropathy syndrome (PDNS) (Zhang et al., 2019).

Similar to the PCV genome, the PCV4 genome is also circular single-stranded DNA and contains two major open reading frames. Genomic and phylogenetic analyses revealed that PCV4 has the closest relationship to mink circovirus (MiCV), which is associated with enteric disease (Zhang et al., 2019). However, knowledge about the infection rate and pathogenicity of this virus is limited. Consequently, we became interested in understanding the seroprevalence of PCV4, preferably using a molecular approach that facilitates any necessary genetic analyses.

\section{MATERIALS AND METHODS}

\subsection{Sample information}

From 2015 to 2019, tissue samples $(\mathrm{n}=93)$ and serum samples $(\mathrm{n}=164)$ of pigs were collected from 15 swine farms in Nanning, Guilin, Fangchenggang, Beihai, Baise, and Hezhou in Guangxi Province, China (Figure 1). Of these, 17 tissue samples and 11 serum samples were from swine with severe clinical signs, including respiratory disease, lymphadenopathy and PDNS. This study received animal ethics approval (No. Xidakezi2000138) from Guangxi University (see ethics approval and consent to participate).

\subsection{DNA isolation and polymerase chain reaction (PCR)}

The viral genome was extracted from swine serum or tissue using the EasyPure Viral DNA/RNA Kit (TransGen Biotech, Beijing, China) according to the manufacturer's instructions. Two primer pairs were 
designed based on the reference sequences of the PCV4/HNU-AHG1-2019 strain (NO. MK986820.1), and published primers and protocols were used to detect PCV4 (Table S1). The PCR mixture contained $2 \mu \mathrm{L}$ of extracted DNA, $2 \mu \mathrm{L}$ of primer pairs $(10 \mu \mathrm{M}), 25 \mu \mathrm{L}$ of $2 \times$ Phanta Max Master Mix (Vazyme, Nanjing, China), and $21 \mu \mathrm{L}$ of DNase/RNase-Free water. The PCR amplification conditions were as follows: predenaturation for $3 \mathrm{~min}$ at $95{ }^{\circ} \mathrm{C}$; followed by 35 cycles of $15 \mathrm{~s}$ at $95{ }^{\circ} \mathrm{C}, 15 \mathrm{~s}$ at $62{ }^{\circ} \mathrm{C}$, extension for $1 \mathrm{~min}$ at $72{ }^{\circ} \mathrm{C}$; and a final extension for 5 min at $72{ }^{\circ} \mathrm{C}$. Subsequently, the PCR products were separated using $1.2 \%$ agarose gel electrophoresis of DNA and cloned into a pMD18-T vector (Takara Co. Dalian). The recombinant vectors were amplified in Escherichia coli (E. coli , DH5 $\alpha$ ) for sequencing.

\subsection{Multiple sequence alignment and phylogenetic analysis}

The genome sequences of PCV4 obtained in this study have been deposited in GenBank under the accession numbers MT311852-MT311854. Multiple sequence alignments were carried out using the Megalign program within the Lasergene package (DNAStar software, DNASTAR Inc.), and phylogenetic relationships were assessed with MEGA software (version 7). Support for the phylogenetic relationships was determined by bootstrapping (1000 replicates). In the present study, the method described by Zhang et al. was used to divide the clades of PCV4 (Zhang et al., 2019).

\section{RESULT AND D ISCUSSION}

Farm workers and all species of farm animals can be infected by circovirus (Li et al., 2011). Multiple studies have indicated that three circovirus species can infect pigs. PCV2 and PCV3 are recognized as the main pathogens in PCV-associated disease (PCVAD) and cause severe economic loss to the swine industry worldwide (Liu et al., 2019; Wang, Cao, et al., 2019; Wen et al., 2018). Recently, a novel and genetically divergent circovirus, PCV4, was considered to be a new pathogen of respiratory disease, diarrhea and PDNS (Zhang et al., 2019).

In the present study, with reference to the method of Zhang et al. (Zhang et al., 2019), a TaqManß) real-time PCR assay was used to detect PCV4 in clinical samples collected between 2015 and 2019 from Guangxi Province, China. The results showed that 5.1\% (13/257) of the porcine samples collected from six cities were PCV4 positive. Eight of 93 tissue samples were PCV4 positive, and 5 of 164 serum samples were PCV4 positive. Six porcine samples with PDNS and two porcine samples with respiratory disease were PCV4 positive. Coinfection of pigs with PCV2 and PCV3 is known to exacerbate disease severity. Further detection showed that 9 of $13(69.2 \%)$ samples were coinfected with PCV2 (n=7) or PCV3 (n=3). Sample NN88 from Nanning was coinfected with PCV2 and PCV3 at the same time.

To analyze the genetic relationship between PCV4 strains and other representative circoviruses, three complete genome sequences (GX2020/NN88, GX2020/GL69, GX2020/FCG49) of PCV4 were obtained. All strains in this study had genomes that were 1770 bp long. Similar to PCVs, the three Guangxi strains of PCV4 also contain two major ORFs. ORF1 encodes the Rep protein (296 amino acids), and ORF2 encodes the Cap protein (228 amino acids). The amino (N) terminus of the Rep protein contains 3 conserved amino acid motifs: RCR motif I (FTLNN), RCR motif II (PHLQG) and RCR motif III (YCSK). The C terminus contains the dNTP binding site GVGKS. The PCV4 genome has two noncoding intergenic regions (IRs) between the 5'- and 3'- ends of the two major ORFs. A stem loop was detected in the genome of PCV4, and it contains 11 bases (TTCAGTATTAC) instead of the 9 bases previously reported (Figure 2) (Zhang et al., 2019).

Multiple sequence alignment of the PCV4 strains in this study showed that the sequences in their genomes shared 5.1\%-73.8\% nucleotide identity with all available reference sequences in the complete genome. Furthermore, the PCV4 strains in this study shared $98.5 \%-99.1 \%$ and $99.7 \%-99.8 \%$ nucleotide identity with other PCV4 strains and each other, respectively. An amino acid sequence comparison showed that the Rep protein and Cap protein the PCV4 strains in this study shared $5.1 \%-80.5 \%$ and $17.8 \%-70.6 \%$ identity with those of all available reference strains. Interestingly, multiple sequence alignment results based on three different methods have confirmed that PCV4 shares the highest homology with MiCV $(73.8 \%$ for the complete genome, $80.5 \%$ for the Rep protein and $70.6 \%$ for the Cap protein). However, multiple sequence alignment 
results showed that PCV4 shares relatively low nucleic acid and amino acid identity ([?] 50\%) with PCV1, PCV2, and PCV3 (Table 1).

In circoviruses, Cap is the sole structural protein and contains immunologically important epitopes associated with virus neutralization (Lekcharoensuk et al., 2004; Meng, 2013). Therefore, it has been the main target for vaccines. At present, commercial vaccines against PCV2 have been introduced worldwide, and they have been considered a successful story in veterinary vaccinology (Park et al., 2019). The Cap protein of PCV4 shares a low amino acid sequence similarity $(<30 \%)$ with that of PCV3. Thus, cross protection seems unlikely. Interestingly, the Cap protein of PCV4 has relatively high homology (approximately 50\%) with those of PCV1 and PCV2. Several previous studies have reported the antigenic site (Lekcharoensuk et al., 2004; Mahe et al., 2000; Shang et al., 2009) and receptor binding site $\left({ }^{98} \mathrm{IRKVKV}^{103}\right)$ of the Cap protein of PCV2 (Misinzo et al., 2006). In this study, multiple sequence alignment analysis of the amino acid sequence of the Cap protein revealed that PCV2 and PCV4 have multiple highly homologous antigen sites and identical receptor binding sites (Figure 3). Therefore, PCV2 and PCV4 may have cross-protective immunogenicity.

To promote understanding of the genetic relationship between the different strains identified in the present study, a phylogenetic tree was constructed using the maximum likelihood method based on the complete genome and the amino acid sequences of the Rep and Cap proteins. Interestingly, the results were similar using the different algorithms. The results confirm that PCV4 had a close relationship to MiCV and batassociated circovirus, followed by PCV1 and PCV2. PCV4 and PCV3 are not in the same branch and are distant from each other (Figure 4). Limited numbers of sequences, however, resisted independent evolution analysis on PCV4. Furthermore, multiple studies have indicated that PCV2 and PCV3 are transmitted to nonporcine hosts, possibly through cross-species transmission routes (Song et al., 2019; X. Wang et al., 2018; J. Zhang et al., 2018). Can PCV4 also infect nonporcine hosts? Further studies are needed to answer this question.

Overall, this research is the first report to detect PCV4 in Guangxi Province, China, and to obtain three complete genomic sequences. Our results combined with those of other reports suggest that PCV4 may commonly circulate within swine herds in South China. This research detected PCV4 in swine with PDNS, and whether PCV4 infection is related to PDNS still needs further research to confirm. Further studies are warranted to elucidate the prevalence and pathogenesis of this novel circovirus.

\section{ACKNOWLEDGMENTS}

This work was supported by the Guangxi Provincial Aquatic Animal Husbandry Technology Application Project (grant number GYMK201528046), the Guangxi Aquatic Animal Husbandry Technology Popularization and Application Project (grant number GYMK201528046), the Guangxi Agricultural Science and Technology Self-financing Project (grant number Z201986) and the Youth Fund Project of Zhejiang Natural Science Foundation (grant number LQ19C180001).

\section{CONFLICTS OF INTEREST}

The authors have no conflicts of interest regarding the research, authorship, and/or publication of this article.

\section{AVAILABILITY OF DATA AND MATERIALS}

The data set supporting the conclusions of this article is available in GenBank.

\section{REFERENCES}

Cao, L., Sun, W., Lu, H., Tian, M., Xie, C., Zhao, G., . . . Qian, A. (2018). Genetic variation analysis of PCV1 strains isolated from Guangxi Province of China in 2015. BMC Vet Res, 14 (1), 43.https://doi:10.1186/s12917$018-1345-z$

Lekcharoensuk, P., Morozov, I., Paul, P. S., Thangthumniyom, N., Wajjawalku, W., \& Meng, X. J. (2004). Epitope mapping of the major capsid protein of type 2 porcine circovirus (PCV2) by using chimeric PCV1 
and PCV2. Journal of Virology, 78 (15), 8135-8145.https://doi:10.1128/jvi.78.15.8135-8145.2004

Li, L., Shan, T., Soji, O. B., Alam, M. M., Kunz, T. H., Zaidi, S. Z., \& Delwart, E. (2011). Possible cross-species transmission of circoviruses and cycloviruses among farm animals. J Gen Virol, 92 (Pt 4), 768-772.https://doi:10.1099/vir.0.028704-0

Liu, Y., Zhang, S., Song, X., Hou, B., Gu, X., Zhao, B., . . . Zhou, Z. (2019). The Prevalence of Novel Porcine Circovirus Type 3 (PCV3) Isolates in Pig Farms in China. Transboundary and Emerging Diseases .https://doi:10.1111/tbed.13266

Mahe, D., Blanchard, P., Truong, C., Arnauld, C., Le Cann, P., Cariolet, R., . . . Jestin, A. (2000). Differential recognition of ORF2 protein from type 1 and type 2 porcine circoviruses and identification of immunorelevant epitopes. J Gen Virol, 81 (Pt 7), 1815-1824.https://doi:10.1099/0022-1317-81-7-1815

Mayr, A., Bachmann, P. A., Siegl, G., Mahnel, H., \& Sheffy, B. E. (1968). Characterization of a small porcine DNA virus. Arch Gesamte Virusforsch, 25 (1), 38-51.

Meng, X. J. (2013). Porcine circovirus type 2 (PCV2): pathogenesis and interaction with the immune system. Annu Rev Anim Biosci, 1, 43-64.https://doi:10.1146/annurev-animal-031412-103720

Misinzo, G., Delputte, P. L., Meerts, P., Lefebvre, D. J., \& Nauwynck, H. J. (2006). Porcine circovirus 2 uses heparan sulfate and chondroitin sulfate B glycosaminoglycans as receptors for its attachment to host cells. Journal of Virology, 80 (7), 3487-3494.https://doi:10.1128/jvi.80.7.3487-3494.2006

Palinski, R., Pineyro, P., Shang, P., Yuan, F., Guo, R., Fang, Y., . . . Hause, B. M. (2017). A Novel Porcine Circovirus Distantly Related to Known Circoviruses Is Associated with Porcine Dermatitis and Nephropathy Syndrome and Reproductive Failure. Journal of Virology, 91 (1).https://doi:10.1128/jvi.01879-16

Park, K. H., Oh, T., Yang, S., Cho, H., Kang, I., \& Chae, C. (2019). Evaluation of a porcine circovirus type 2a (PCV2a) vaccine efficacy against experimental PCV2a, PCV2b, and PCV2d challenge. Vet Microbiol, 231 , 87-92.https://doi:10.1016/j.vetmic.2019.03.002

Shang, S. B., Jin, Y. L., Jiang, X. T., Zhou, J. Y., Zhang, X., Xing, G., . . . Yan, Y. (2009). Fine mapping of antigenic epitopes on capsid proteins of porcine circovirus, and antigenic phenotype of porcine circovirus type 2. Mol Immunol, 46 (3), 327-334.https://doi:10.1016/j.molimm.2008.10.028

Song, T., Hao, J., Zhang, R., Tang, M., Li, W., Hui, W., . . . Ma, Z. (2019). First detection and phylogenetic analysis of porcine circovirus type 2 in raccoon dogs. BMC Vet Res, 15(1), 107.https://doi:10.1186/s12917019-1856-2

Sun, W., Wang, W., Xin, J., Cao, L., Zhuang, X., Zhang, C., . . . Jin, N. (2019). An epidemiological investigation of porcine circovirus 3 infection in dogs in the Guangxi Province from 2015 to 2017, China. Virus Res, 270 , 197663.https://doi:10.1016/j.virusres.2019.197663

Tischer, I., Gelderblom, H., Vettermann, W., \& Koch, M. A. (1982). A very small porcine virus with circular single-stranded DNA.Nature, 295 (5844), 64-66.https://doi:10.1038/295064a0

Wang, W., Cao, L., Sun, W., Xin, J., Zheng, M., Tian, M., . . . Jin, N. (2019). Sequence and phylogenetic analysis of novel porcine parvovirus 7 isolates from pigs in Guangxi, China. PLoS One, 14 (7), e0219560.https://doi:10.1371/journal.pone.0219560

Wang, W., Sun, W., Cao, L., Zheng, M., Zhu, Y., Li, W., . . . Jin, N. (2019). An epidemiological investigation of porcine circovirus 3 infection in cattle in Shandong province, China. BMC Vet Res, 15 (1), 60.https://doi:10.1186/s12917-019-1793-0

Wang, X., Li, W., Xu, X., Wang, W., He, K., \& Fan, H. (2018). Phylogenetic analysis of two goat-origin PCV2 isolates in China. Gene, 651, 57-61.https://doi:10.1016/j.gene.2018.01.095 
Wen, S., Sun, W., Li, Z., Zhuang, X., Zhao, G., Xie, C., . . . Jin, N. (2018). The detection of porcine circovirus 3 in Guangxi, China.Transboundary and Emerging Diseases, 65 (1), 27-31.https://doi:10.1111/tbed.12754

Zhang, H. H., Hu, W. Q., Li, J. Y., Liu, T. N., Zhou, J. Y., Opriessnig, T., \& Xiao, C. T. (2019). Novel circovirus species identified in farmed pigs designated as Porcine circovirus 4, Hunan province, China. Transboundary and Emerging Diseases .https://doi:10.1111/tbed.13446

Zhang, J., Liu, Z., Zou, Y., Zhang, N., Wang, D., Tu, D., . . . Wang, N. (2018). First molecular detection of porcine circovirus type 3 in dogs in China. Virus Genes, 54(1), 140-144.https://doi:10.1007/s11262-0171509-0

TABLE 1 Identities (\%) shared between porcine circovirus 4 (PCV4) and other members of the genus Circovirus

\begin{tabular}{llll}
\hline Name & PCV4 & PCV4 & PCV4 \\
\hline & The complete genome (\%) & The Rep protein (\%) & The Cap protein (\%) \\
Bat-associated circovirus & 44.6 & 76 & 41.5 \\
Bat circovirus & 65.3 & 52.6 & 28.8 \\
Beak and feather disease virus & 39.7 & 6.2 & 25.4 \\
Canine circovirus & 46.4 & 50.3 & 18.5 \\
Columbid circovirus & 41.6 & 48.6 & 23.2 \\
Duck circovirus & 40.9 & 49 & 24.8 \\
Finch circovirus & 42.7 & 49.1 & 27.1 \\
Fox circovirus & 46.7 & 52.4 & 18.5 \\
Goose circovirus & 44.6 & 47.9 & 23.6 \\
Gull circovirus & 38.3 & 45.7 & 26.2 \\
Mink circovirus & 73.8 & 80.5 & 70.6 \\
Chicken anemia virus & 25.3 & 5.1 & 17.8 \\
Raven circovirus & 40.7 & 47.4 & 25.6 \\
Starling circovirus & 43.9 & 50.5 & 23.2 \\
Porcine circovirus 1 & 61.2 & 49.8 & 46.4 \\
Porcine circovirus 2 & 60.9 & 48.3 & 50 \\
Porcine circovirus 3 & 41.8 & 47.6 & 26 \\
\hline
\end{tabular}

FIGURE 1 Geographical information for samples collected in Guangxi, China. Red stars indicate the geographical location of the samples. 


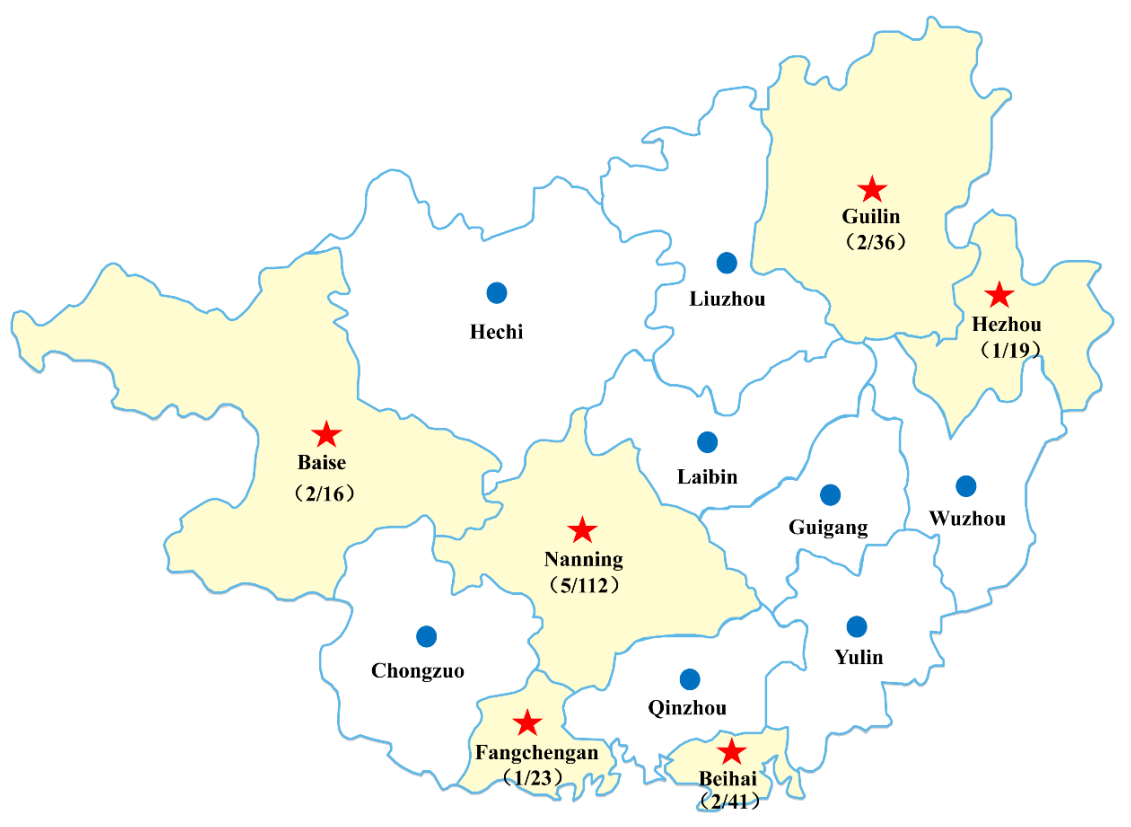

FIGURE 2 Predicted genome organization of PCV4 (A) and the stem loop of PCV4 (B). A B 


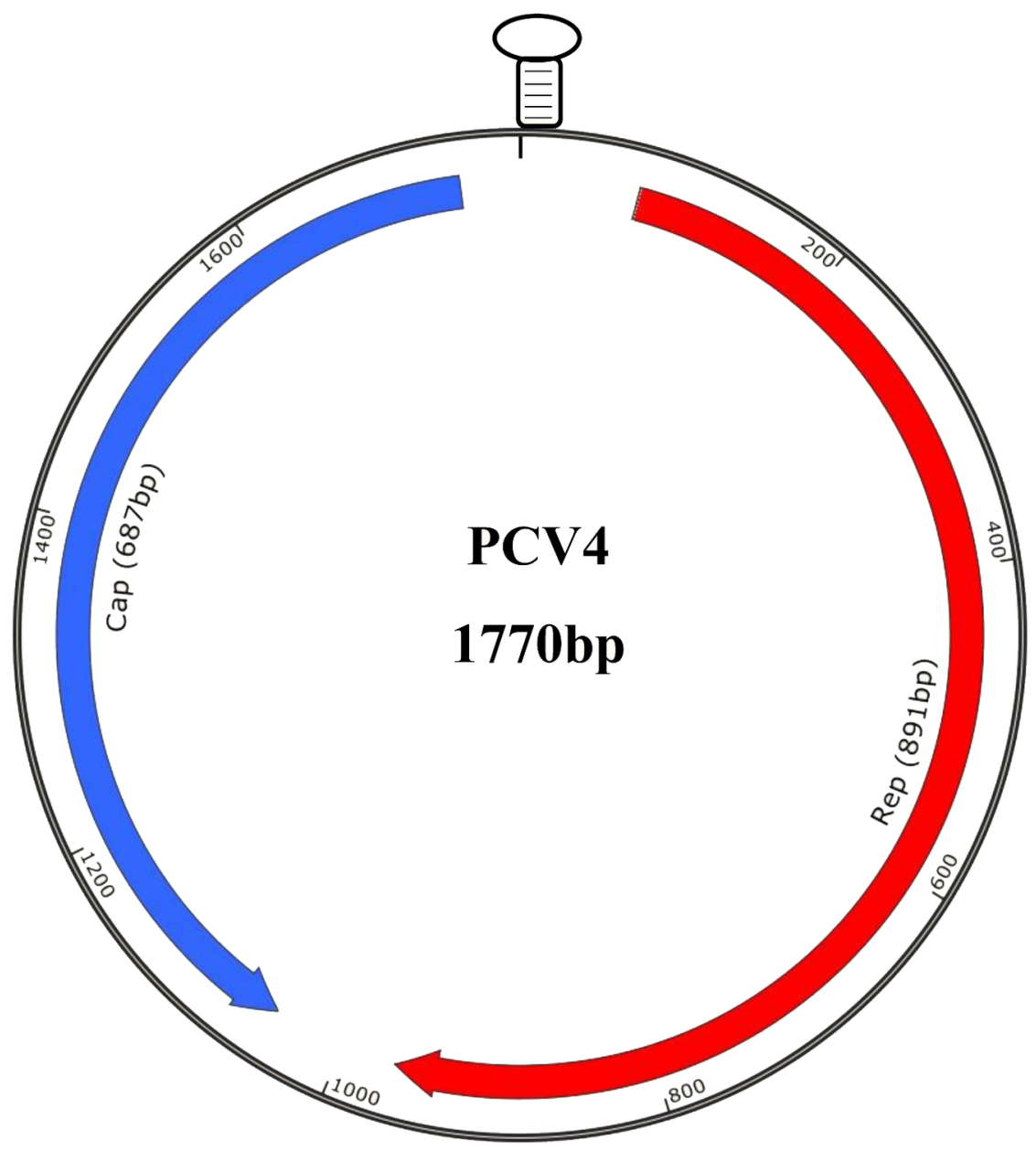




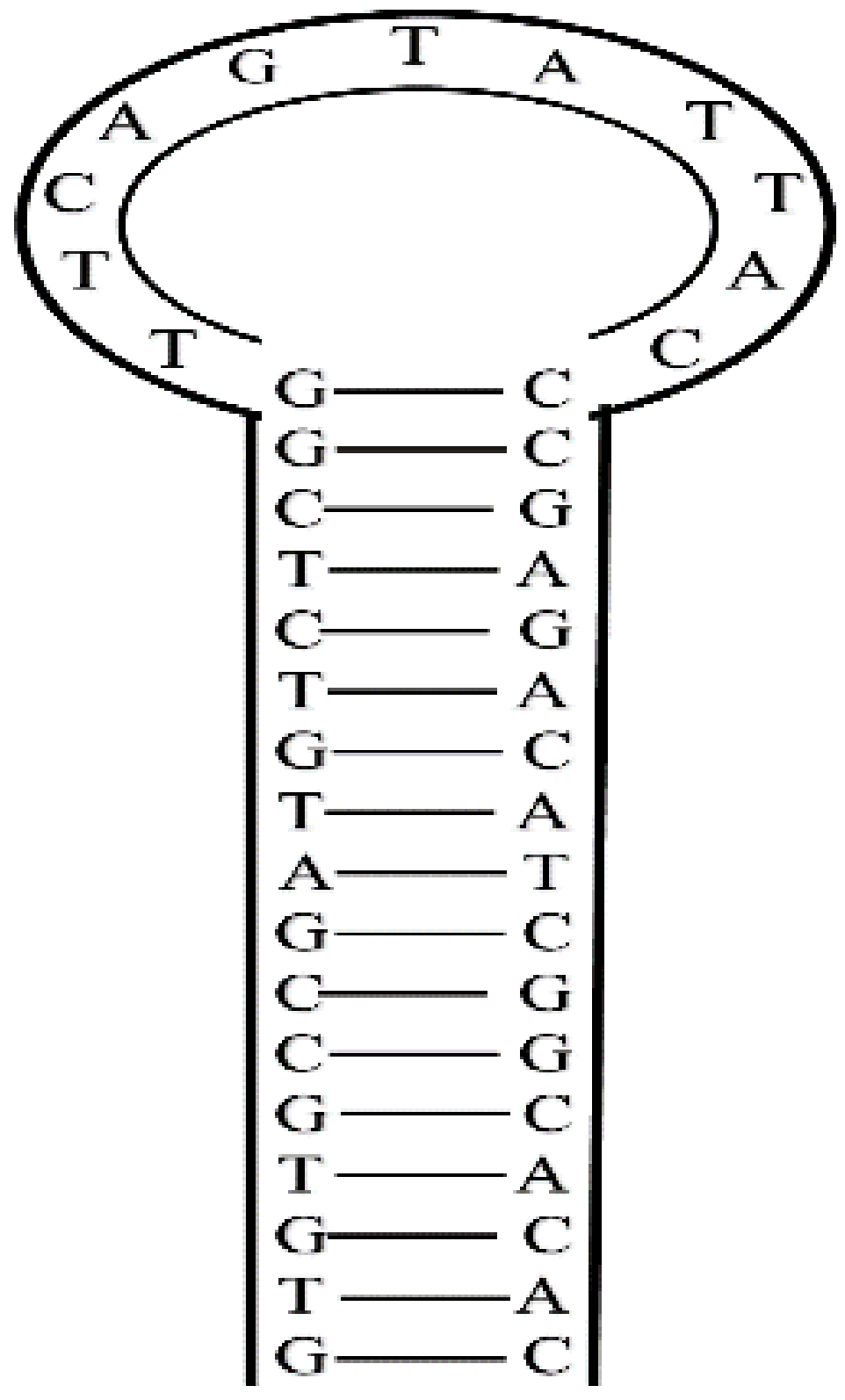

FIGURE 3 Multiple sequence alignment analysis of the amino acid sequence of the Cap protein in porcine circovirus 4 (PCV4) and PCV2. Black boxes indicate antigen sites, and yellow boxes indicate receptor binding sites. 

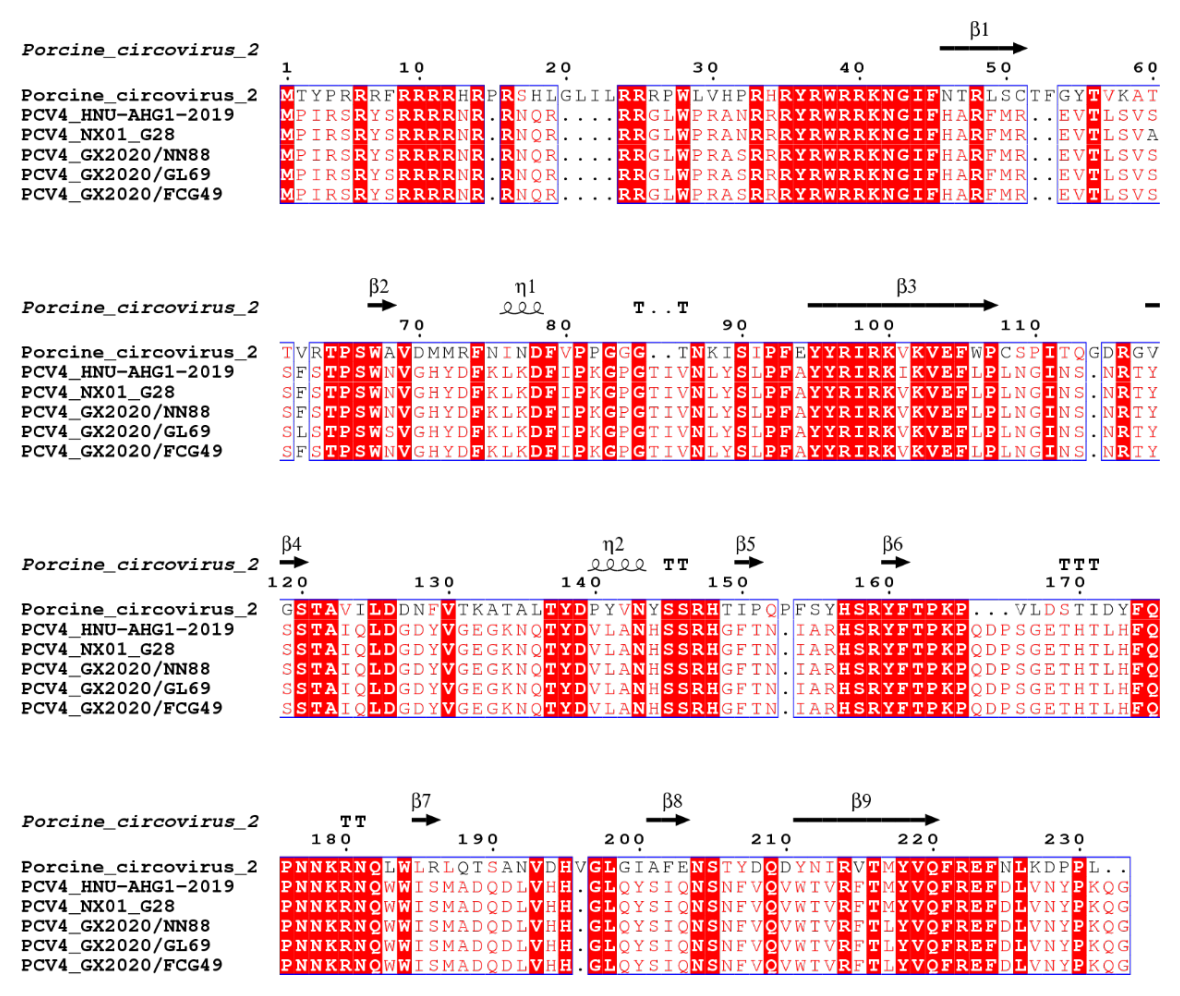

FIGURE 4 Phylogenetic analysis based on the complete genome (A) and the amino acid sequences of the Rep protein (B) and Cap protein (C).

A

\section{Hosted file}

image5.emf available at https://authorea.com/users/314652/articles/445036-detection-and-geneticcharacterization-of-porcine-circovirus-4-pcv4-in-guangxi-china

$\mathrm{B}$

\section{Hosted file}

image6. emf available at https://authorea.com/users/314652/articles/445036-detection-and-geneticcharacterization-of-porcine-circovirus-4-pcv4-in-guangxi-china

$\mathrm{C}$

\section{Hosted file}

image7. emf available at https://authorea.com/users/314652/articles/445036-detection-and-geneticcharacterization-of-porcine-circovirus-4-pcv4-in-guangxi-china

\section{Supporting Information}

Table S1. List of primer sequences used in this study.

\begin{tabular}{lll}
\hline Primer & Sequence (5'-3') & Reference \\
\hline PCV4-F & GGAACGACAAGGACGACACTT & For detecting PCV4 (Zhang et al., \\
& $2010)$ \\
PCV4-R & CTTGAGGCTCTGGTATCTTATTGC
\end{tabular}




\begin{tabular}{|c|c|}
\hline Primer & Sequence (5'-3') \\
\hline PCV4-TZ & $\begin{array}{l}\text { FAM- } \\
\text { CCGCCCTGAATGCCGGCAGCTCAATG- } \\
\text { BHQ1 }\end{array}$ \\
\hline PCV4-1-F & $\begin{array}{l}\text { CAGTATTACCCGAGACATCGGCAGASendiGersequencing, this } \\
\text { study. }\end{array}$ \\
\hline PCV4-873-R & GGGCTCTGATATCCACTTTCAGCTCCACAT \\
\hline PCV4-775-F & $\begin{array}{l}\text { GTTCCATTGAGTTCGTGGCCAAGoA GAnome sequencing, this } \\
\text { study. }\end{array}$ \\
\hline PCV4-115-R & GTGAAACAATATCTCTTCACGGGGTG \\
\hline
\end{tabular}

Zhang, H. H., Hu, W. Q., Li, J. Y., Liu, T. N., Zhou, J. Y., Opriessnig, T., \& Xiao, C. T. (2019). Novel circovirus species identified in farmed pigs designated as Porcine circovirus 4, Hunan province, China. Transboundary and Emerging Diseases .https://doi:10.1111/tbed.13446 